Rabaska

Revue d'ethnologie de l'Amérique française

\title{
Été 1958, Luc Lacourcière en Acadie
}

\section{Georges Arsenault}

Volume 17, 2019

URI : https://id.erudit.org/iderudit/1066021ar

DOI : https://doi.org/10.7202/1066021ar

Aller au sommaire du numéro

Éditeur(s)

Société québécoise d'ethnologie

ISSN

1703-7433 (imprimé)

1916-7350 (numérique)

Découvrir la revue

Citer ce document

Arsenault, G. (2019). Été 1958, Luc Lacourcière en Acadie. Rabaska, 17, 273-278.

https://doi.org/10.7202/1066021ar

Ce document est protégé par la loi sur le droit d'auteur. L'utilisation des services d'Érudit (y compris la reproduction) est assujettie à sa politique d'utilisation que vous pouvez consulter en ligne.

https://apropos.erudit.org/fr/usagers/politique-dutilisation/
Cet article est diffusé et préservé par Érudit.

Érudit est un consortium interuniversitaire sans but lucratif composé de l'Université de Montréal, l'Université Laval et l'Université du Québec à Montréal. Il a pour mission la promotion et la valorisation de la recherche. https://www.erudit.org/fr/ 


\title{
Anniversaire
}

\section{Été 1958, Luc Lacourcière en Acadie}

\author{
Georges Arsenault \\ Ethnologue, Île-du-Prince-Édouard
}

\section{«Chers et regrettés amis "}

Quand je suis allé étudier le folklore à l'Université Laval en 1974, j'ai eu la chance de rencontrer le professeur Luc Lacourcière, fondateur des Archives de folklore de cette université. À plusieurs reprises, il m'a raconté ses visites à l'Île-du-Prince-Édouard en 1957, 1958 et 1959 pour enregistrer des chansons, des contes et des reels traditionnels. Il m'a même embauché pour transcrire la plupart des contes qu'il avait trouvés dans la communauté acadienne. Il ne conservait que de beaux souvenirs des gens qu'il avait rencontrés, particulièrement deux conteuses et chanteuses, soit Eulalie (Lalie à Jack) Arsenault de Saint-Chrysostome et Délia Perry [Poirier] de Baie-Egmont.

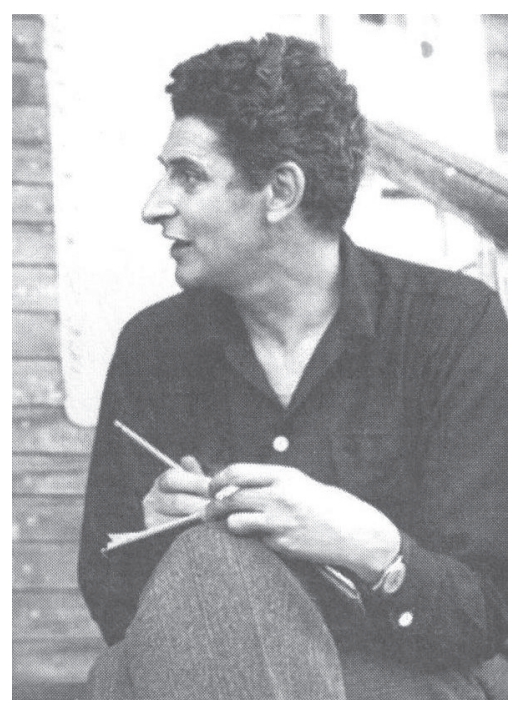

Luc Lacourcière (1910-1989) 
Lors de sa visite à l'île en 1958, Luc Lacourcière était accompagné de Simonne Voyer qui faisait une recherche sur la danse traditionnelle. Le 14 août, ils ont été invités à une soirée chez le violoneux Eddy Arsenault, à Saint-Chrysostome. Lacourcière y a enregistré des chansons, des contes et de la musique traditionnelle d'Eulalie Arsenault, Délia Perry, Eddy Arsenault, Amand Arsenault, Marguerite (à Philippe) Arsenault et du jeune Éloi Arsenault.

J'ai trouvé dans les archives de Lacourcière à l'Université Laval une « adresse » qui lui a été lue ce soir-là, ainsi qu'à Simonne Voyer. J'ai l'impression qu'elle a été écrite par Délia Perry. Ce compliment témoigne de l'amitié et de l'admiration que les gens de Baie-Egmont avaient développées envers ces deux folkloristes du Québec. Voici le texte.

\section{Chers et regrettés amis.}

Nous sommes attristés ce soir en venant vous dire ce que ressent [ent] nos coeurs en ce moment, à l'occasion de votre prochain départ. Nous vous souhaitons de grand cœur les vœux de bonne chance, et aussi l'aurevoir qui nous semble déjà si lointain. Nos cours déjà attristés ne savent comment s'exprimer, en se voyant près de se sépar [er] de si bons amis. Oui, votre départ nous attriste, car, à la pensée que vous allez nous quitter, pour peut-être ne plus jamais nous revoir, [cela] nous attriste davantage. Nous manquerons certainement des amis, des amis sincères et bons, que nous ne pourrons oublier, et que nous aurions voulu garder avec nous longtemps. Mais soyez assurés que nous garderons longtemps un doux souvenir de vous, espérant que Dieu vous gardera la vie et la santé pour de nombreuses années encore, et que nous aurons la joie de vous revoir bientôt. Encore une fois nous vous souhaitons bonne chance et bon voyage, et veuillez accepter ces petits souvenirs comme preuve et de notre sincère amitié.

Vos amis de la paroisse d'Egmont Baie, I.-P.-É. Ce 14 août 1958

Tous les enregistrements que Lacourcière a faits à l'Île sont conservés dans les archives de l'Université Laval. Une copie se trouve aussi au Centre d'études acadiennes Anselme-Chiasson à l'Université de Moncton.

\section{Eulalie Arsenault}

L'une des informatrices préférées de Luc Lacourcière à l'Île-du-PrinceÉdouard était la chanteuse et conteuse Eulalie Arsenault (1877-1966). Le folkloriste de l'Université Laval l'a rencontrée dès sa première visite à l'Île en 1957 et lors de ses tournées d'enquêtes subséquentes en 1958 et 1960. Eulalie Arsenault, affectueusement appelée Mémé Lalie ou Tante Lalie par 
les gens de son village, était effectivement la grand-mère, l'arrière-grandmère, la tante et la grand-tante d'un très grand nombre de gens du village de Saint-Chrysostome. En 1893, à l'âge de 16 ans, elle épousait Jean-Pierre Arsenault, mieux connu comme Jack à Philias. Eulalie, également née Arsenault, a donné naissance à 15 enfants dont deux sont décédés en bas âge. Femme joviale et divertissante, Lalie à Jack, était de toutes les rencontres. Aucune soirée ne pouvait se dérouler dans sa communauté sans qu'elle y soit invitée, que ce soit une noce, un anniversaire de mariage, un frâlic à filer ${ }^{1}$, et quoi encore. Véritable boute-en-train, elle y allait de ses farces, de ses chansons, de ses turluttes et de ses pas de gigue. Eulalie Arsenault est décédée en 1968 à l'âge de 89 ans.

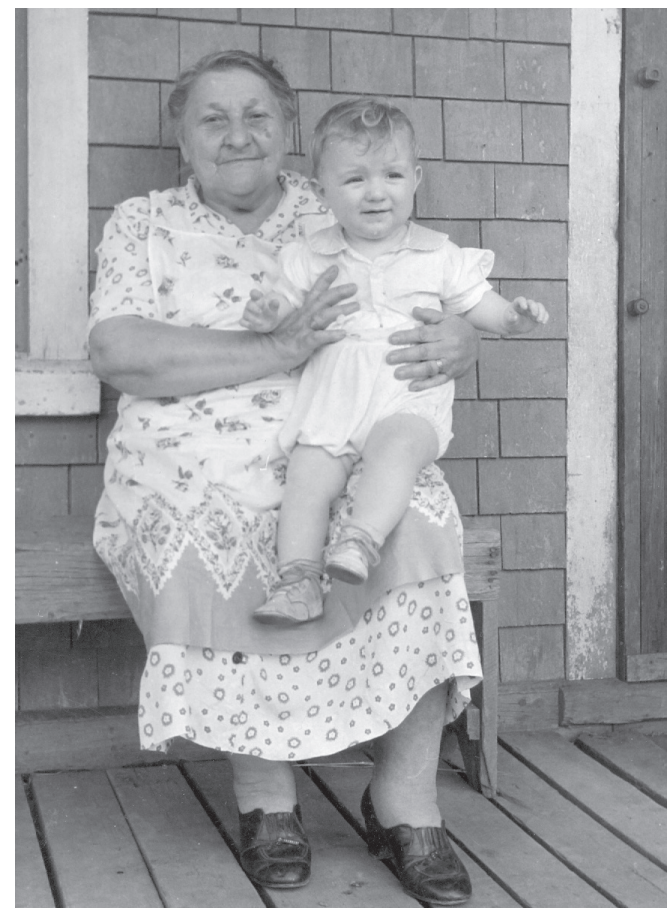

Lalie à Jack Arsenault (1877-1966) en 1960

Photo : coll. Georges Arsenault

\section{Délia Perry (née Gallant)}

Née à Saint-Chrysostome, Île-du-Prince-Édouard, le 24 juillet 1899, Délia Gallant a fréquenté l'école du village pendant sept ans. Avant de se marier, elle a travaillé comme servante dans 28 familles et elle a vécu pendant de courtes

1. Frâlic ou frolic. Selon Yves Cormier, Dictionnaire du français acadien (Éditions Fides, 1999), «Frolic [...] Rassemblement de personnes pour effectuer une tâche commune, notam. construire un bâtiment (par ex., une grange), éplucher le maïs, couper le bois, et qui se termine par un repas en commun et une soirée musicale. » Au Québec, on dit plutôt corvée. 
périodes à Chelsea, Massachusetts, et à Rogersville, Nouveau-Brunswick. À l'âge de 31 ans, Délia épouse le veuf Dan Perry [Daniel Poirier], un barbier et charpentier de Summerside, père de quatre enfants. Délia donne naissance à 11 enfants dont deux meurent peu de temps après la naissance. En 1949, Dan meurt et, âgée de 50 ans, Délia se retrouve veuve et presque sans moyens pour élever sa grande famille. Un mois avant la mort de Dan, la famille quitte la ville de Summerside pour le village natal de Délia. Elle passe une douzaine d'années dans la région où elle renoue avec une tradition familiale, soit celle du conte. Elle devient une conteuse fort appréciée dans son voisinage. Un hiver, elle allait dire ses contes jusqu'à trois fois par semaine. Son répertoire était vaste. Il comprenait des contes traditionnels, mais aussi des récits qu'elle retenait de ses lectures dans des livres et dans l'hebdomadaire insulaire, L'Impartial. Pendant sa jeunesse, elle lisait abondamment à son frère aveugle, autant en anglais qu'en français. En 1957-1958, sans avoir épuisé son répertoire, elle a raconté 90 contes à Luc Lacourcière. Délia est décédée à Toronto le 26 novembre 1967, quelques semaines après avoir été heurtée par une voiture. Elle y était déménagée pour vivre avec sa plus jeune fille.

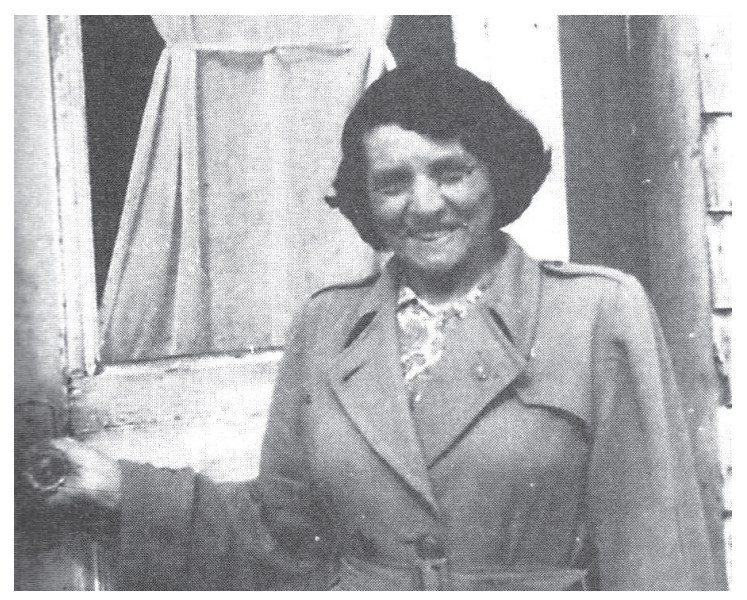

Délia Gallant (1899-1967) vers 1955

Photo : coll. Georges Arsenault

\section{NDLR}

En 1983, Luc Lacourcière accordait de longs entretiens à Jean Blouin sur les circonstances des enquêtes qu'il avait menées au Québec et dans les Maritimes. Ses propos, enregistrés pour la série « De mémoire d'homme », insistaient sur la concordance entre l'abondante matière orale recueillie et la personnalité attachante de certains des informateurs rencontrés au cours de son itinéraire; en revisitant ses souvenirs, illustrés de péripéties et d'anecdotes 
bien choisies, Lacourcière dévoila aux auditeurs sa « petite géographie cordiale », un témoignage d'une grande humanité rempli de gratitude envers ses généreux collaborateurs ${ }^{2}$. Extraits du cinquième et dernier entretien, portant sur l'Île-du-Prince-Édouard, les passages qui suivent relatent son expérience de terrain et, tout spécialement, l'évocation de ses deux principales informatrices.

\section{L'Île-du-Prince-Édouard}

Je suis retourné à trois reprises à l'Île-du-Prince-Édouard. Ce qui m'est resté comme caractéristique de cette population-là, ça a été le caractère absolument enjoué de cette population-là et, en particulier, des veillées, des attroupements qui se faisaient dans les maisons à l'occasion des enregistrements. Là, j'étais un peu comme le maître de cérémonie ; je cherchais les informateurs. Il y en a qui se présentaient, il y en a qui se faisaient prier et on enregistrait toute la soirée, alternant des contes ou des fabliaux, surtout des fabliaux assez courts, et ce que les Acadiens appelaient des «tours ». [Luc Lacourcière, «De mémoire d'homme », épisode 5, 26 juillet 1983, p. 4]

\section{Eulalie Arsenault}

Ce qui m'a touché le plus, de cette vieille dame Arsenault que tout le monde appelait la tante Lalie - tout le monde la connaissait sous le nom de tante Lalie et c'est sûr qu'on en garde encore le souvenir à l'Île-duPrince-Édouard-elle me dit ceci : «On ne vous a pas connu longtemps, maintenant vous allez vous ennuyer. Vous allez partir et on va s'ennuyer de vous. " Ça, c'étaient des témoignages d'informateurs que je trouvais bien touchants. [Ibid., p. 4]

\section{Délia Gallant [veuve Daniel Poirier]}

Dans la Baie-Egmont, il y avait un endroit qui s'appelait Wellington. [...] Là, j'avais une dame Poirier qui a été probablement la dame la plus prolifique au point de vue des contes populaires. J'ai recueilli d'elle audelà de cent contes, des contes merveilleux, de longs contes merveilleux et aussi des contes facétieux, bien sûr. C'était la personne au répertoire le plus extraordinaire. Et comme elle était veuve et donc libre de son temps,

2. Les cinq épisodes hebdomadaires de la série « De mémoire d'homme - Luc Lacourcière » ont été présentés au réseau français de la Société Radio-Canada entre le 28 juin et le 26 juillet 1983. Le Service de la transcription et dérivés de la radio en a tiré cinq cahiers numérotés : 1 - La Beauce et Lotbinière (28 juin 1983, 10 p.) ; 2 - Charlevoix et le Saguenay (5 juillet 1983, 10 p.) ; 3 - Bellechasse et L'Islet (12 juillet 1983, 10 p) ; 4 - Le Nouveau-Brunswick (19 juillet 1983, 8 p.) ; 5 - L'île-du-PrinceÉdouard (26 juillet 1983, 9 p.). Émissions de 30 min. Recherchiste et interviewer : Jean Blouin ; réalisateur : André Major. Transcription : 47 p. ms. 
j'allais chez elle et j'enregistrais l'avant-midi, l'après-midi et la soirée. En l'espace d'une semaine, c'est assez phénoménal, j'ai recueilli d'elle soixante-quatorze récits qui sont tous dans un même cahier, tous notés dans ce même cahier que j'ai sous les yeux. [...] Et elle était, je dirais, une conteuse un peu professionnelle parce qu'elle me disait : "Souvent, on m'invite à aller conter, l'hiver, dans telle ou telle maison, chez des voisins ou à différents endroits, mais je ne veux pas y aller plus que trois fois par semaine, parce que, si j'y allais plus que ça, les gens diraient que je suis une coureuse. " Alors, vous voyez la candeur, la naïveté de cette brave dame. [Ibid., p. 6]

\section{L'avenir du folklore de l'Île}

Mais dans les jeunes générations, il y a des gens qui sont attentifs à la tradition, Et il s'est fondé depuis un musée à Miscouche, par exemple. On a un ancien étudiant de l'Université qui a pris en main, je dirais, les études de folklore à l'Île-du-Prince-Édouard. C'est Georges Arsenault qui vient de publier un très beau recueil sur les chansons composées à l'Île-du-Prince-Édouard, dont une chanson sur les filles de Rustico que madame Arsenault $m$ 'avait chantée, sur les complaintes locales; il y a eu beaucoup de complaintes locales composées sur des anecdotes ou des événements. Alors, Georges Arsenault a justement fait des études là-dessus. [Ibid., p. 7] 